\title{
A Commentary on a Manuscript Entitled The Psychology of Creativity: A Critical Reading
}

\section{Eric Shiu}

University of Birmingham, United Kingdom

E-mail address: E.C.Shiu@bham.ac.uk

\section{ARTICLE INFO}

\section{Keywords:}

Innovation

Cross-disciplinary cooperation

\section{Article history:}

Received 14 November 2014

Received in revised form 18 December 2014

Accepted 19 December 2014

ISSN: 2354-0036

DOI: 10.15290/ctra.2014.01.02.14

\author{
A B STRACT
}

Dr Eric Shiu agreed with Professor Vlad Petre Glăveanu that although the amount of research on creativity is increasing, a corresponding theoretical breakthrough is not apparent. One main culprit is the overwhelming dominance of the quantitative approach in creativity research. Another is the lack of consensus in the definition of creativity. Shiu draws from his research experience in both innovation and creativity research, and feels that the path of academic development for the innovation field is healthier. For instance there is more consensus in the definition of innovation, the categorization of innovation and the process of innovation than in creativity. Echoing Glăveanu's recommendation to study creativity in its time and space context, Shiu added that the space context should extend to the cultural setting. So far research efforts on creativity are predominantly American and to a lesser extent Western European. As a result, alternative conceptions of creativity nurtured and practised in some other parts of the world may be relatively neglected. Lastly, Shiu is fascinated by the great potential for creativity researchers from different disciplines to conduct cross-disciplinary cooperation and research, but he also warned that creativity research, which is "owned" by many academic disciplines, may suffer from further fragmentation. Effective cross-disciplinary dialogue is needed to combat this danger.

I have the honour to be invited by Dr Maciej Karwowski, co-editor of the journal of Creativity: Theories - Research - Applications to write a commentary on the above manuscript authored by Professor Vlad Petre Glăveanu. I am a fellow creativity researcher, but have to firstly declare that my academic background is related, but clearly different from that of the author, who has developed his expertise in the psychology field in general, and the psychology of creativity in particular. My broad academic background is in management and marketing, within which I have specialized in innovation before discovering creativity research a few years ago. Professor Glăveanu's manuscript covers many im- 
portant issues in the study of the psychology of creativity. I don't feel comfortable in reviewing and commenting on every important issue raised by Professor Glăveanu in his manuscript. I will therefore only review and comment on some, in areas where I have knowledge of the issues concerned.

I totally agree with Professor Glăveanu, that in spite of an ever increasing amount of research on creativity, a corresponding theoretical breakthrough in creativity research is not apparent. The background literature in creativity studies still often refers to famous creativity researchers and the not-so-recent theories they proposed. One of the major culprits, as noted in Professor Glăveanu's manuscript, is that the quantitative approach is overwhelmingly dominant in creativity studies. Indeed, the Creativity Research Journal only considers papers using the quantitative rather than the qualitative approach. However, to explore a new theory and then to test it, the researcher should not refrain from using a variety of research techniques. More often than not, theoretical development requires the use of both quantitative and qualitative approaches, capitalising on the advantages of each and offsetting the disadvantages (Shiu, et al. 2009a) in order to build a valid theory. Another major culprit contributing to a less than satisfactory state of theoretical development in the creativity field is the lack of consensus in the definition of creativity. Dawson \& Andriopoulou (2014) reflect that the number of definitions of creativity is probably the same as the number of academic authors in the creativity field. One old Chinese saying is worth recalling here: before doing anything about something, one needs to give that something a proper definition. Different definitions of creativity lead to different conceptualisations of the nature and scope of creativity as seen by different creativity researchers - this is certainly not a healthy condition in the study of creativity.

As a researcher in both innovation and creativity, I feel I may have a certain level of knowledge to allow me to compare the academic developments between innovation and creativity. Innovation and creativity are very closely linked to each other. Innovation is the de facto application of creativity (Shiu, 2009b). In spite of their close linkage, the two have their own paths of academic development. Comparing the two I feel that the path of academic development for the innovation field is healthier than that for the field of creativity. It is true that there is still no universal definition of innovation, that is followed by all innovation researchers; there are still debates over how to categorize innovation; there are different numbers of stages in the innovation process suggested by different scholars. However the differences in opinion regarding the definition and other issues in the innovation field may not be as big as those in the creativity field. For example, I would be very surprised to find a definition of innovation that is significantly different from that 
proposed by the OECD (1991), which is "an iterative process initiated by the perception of a new market and/or new service opportunity for a technology-based invention which leads to development, production, and marketing striving for the commercial success of the invention." The beauty of this definition, as noted by Garcia \& Calantone (2002), is that it captures the essence of innovation from an overall perspective and addresses two key characteristics of innovation. First, it notes that innovation is not all about the technological development of an invention, but should also consist of the introduction of that invention to end-users through adoption and diffusion. Second, its emphasis on iteration implies that innovation includes both the first introduction of a new innovation and the re-introduction of the same innovation in an improved form. I also doubt that any innovation researcher would challenge the existence and meanings of the two key categories of innovation, i.e. radical innovation and incremental innovation, even though there have been only sporadic studies on the categorization of innovation, such as really new products as noted in Schmidt \& Calantone (1998) and re-innovation as proposed by Cheng \& Shiu (2008). There are, among others, the five-step innovation process as developed by Crawford \& di Benedetto (2011) and the thirteen-activity innovation process as proposed by Cooper \& Kleinschmidt (1986). All these versions of the innovation process comprise a different numbers of steps and use different words to name essentially the same step. Yet in spite of these different versions of the steps of the innovation process, none would argue against the notion that the innovation process must include idea generation/concept development, product development and product launch. Along the path of academic development for innovation, there are different voices on issues such as definition, categorization and process, but the nature of these differences is not too fundamental and is not too chaotic. Probably the same cannot be said of the creativity field, which, in my opinion, may be more chaotic in its academic development. This more chaotic nature is detrimental to the continual theoretical development of the creativity field. The over-emphasis on the quantitative approach in the creativity field as opposed to a more balanced use of qualitative and quantitative approaches in the innovation field also contributes to the difference in the state of health of the academic development of the two fields.

Professor Glăveanu rightly argued that creativity should be studied in its time and space context, as one cannot detach creativity from its context and should not (wrongly) assume that there is no interaction between them, which is in tandem with what Placone (1989) drew attention to in relation to the contextual dynamics of change in the creativity process. As Professor Glăveanu (2014) states: there are very few who would disagree 
with this premise (that creativity can indeed be educated), which implies that the context a person is put into can have an effect on his/her creativity. Indeed not only is context influential with regard to an individual's creativity, but it also provides criteria for judging to what extent a person is creative. Putting today's person, with a certain level of creativity, back 200 years, would almost certainly result in his/her creativity level being judged very differently. By the same token, putting a person from one spatial context into another, would most likely mean that his/her creativity level would be judged differently by his/ her contemporaries in their respective spaces. We need to judge a person's creativity in the context the person is put into. A few years ago, I watched a TV programme introducing a child prodigy in India who was widely praised by people in his village as an extremely creative and talented child. He applied what he knew, together with common sense and logic, to derive new ways of diagnosing and curing diseases. In spite of his creativity and talent, some of his thoughts were still immature and might well have been incorrect. If we were to judge this child on the basis of what he thought and did, he almost certainly would not have received the same level of praise in say the USA where the "context" for nourishing creativity development is better (by the standards of the USA or more broadly by the standards of the West) than that back in an Indian village, which was the context for this child's abilities. In keeping with this line of thinking, both previous and current research efforts on creativity are predominantly American and to a lesser extent those of Western European. These research efforts tend to promote, albeit mostly inadvertently, the orthodoxy of the American-Western European notion of creativity processes, and in so doing, alternative conceptions nurtured and practised in some other parts of the world, may be relatively neglected. As Shiu (2009b) has argued, the resulting problem is two-fold. First, given the potentially vast differences between cultures, models of creativity developed and successfully followed in western culture may not be applicable to a similar extent in another culture. Second, by not giving the creativity behaviours expressed in other cultures the attention they deserve, we as creativity researchers, as well as organizations trying to tap the talents of creativity, are losing the opportunity to make potentially very rewarding use of these alternative conceptions of creativity, not to mention the possibly even more rewarding route that could integrate knowledge in the field of creativity across different cultures in a novel way, thus promoting "out-of-the-culturalbox" creative ideas that could make even greater impacts and contributions.

In the field of innovation, there have been real life cases of cross-cultural learning, such as the example of a leading ice cream company learning from a locally popular taste in Buenos Aires and applying it successfully in new product development, a famous 
sports shoe company learning a new design initiated by a world class footballer from Brazil, and an American jeans company learning a new style of jeans that originated in Japan (Crawford \& di Benedetto, 2011). These are cases of cross-cultural studies in innovation that originate from creative thinking. We need more than case studies. We need to learn the "ways" that have to be there in the first place, that are common in a particular culture and nurture creative thinking. These "ways" can be very different from the models of creativity we, as creativity researchers in the West, have learned. These "ways" cannot be called theories, because they might not have been scientifically proven, but they have been in the culture for hundreds or even thousands of years. Although there have been a number of studies on comparing creativity between cultures (Cheng, 1999; Niu \& Sternberg 2002; Morris \& Leung 2010), they are far and few between and are mostly on making comparisons between West and East. However, we have many other cultures, apart from the Chinese culture or East Asian culture, whose inhabitants may have their unique "ways" of creative thinking, but unfortunately these have not been studied properly. Furthermore most, if not all previous creativity studies making comparisons between cultures have been approached in a broad sense (e.g. intuition versus logic by Wonder \& Blake, 1992) thus not allowing us to study the unique creativity process (the "way" of creative thinking) of a particular culture in adequate detail. We need to open our eyes and minds to try to learn these ways in detail. In order to learn these in an "under-the-skin" manner, we have to be flexible in our approach, as the quantitative approach alone is not enough. To relate what I have discussed and suggested previously to what Professor Glăveanu said, we need to take into account the spatial context when conducting creativity research, and this space can be geographical or cultural.

My final point is probably the only point in which I may not totally agree with Professor Glăveanu. I need to stress that what I have discussed and suggested in all the previous paragraphs results from trying to see the creativity field as a whole, and not just from the perspective of the field of the psychology of creativity. Psychology, in my understanding, briefly speaking, is fundamentally about the study of the human mind, and therefore it may not be particularly "off track" for psychology researchers to just focus on the human mind and study the creativity within it and care very little about the corresponding context. Creativity may be the subject of research and teaching in many disciplines, such as psychology, education, sociology, management, engineering and even perhaps philosophy. The fact that creativity draws interest and input from different disciplines is fascinating, because there is great potential for creativity researchers from different disciplines to conduct cross-disciplinary cooperation and research. However, the same fact may also 
lead to creativity research efforts that are piecemeal and fed by knowledge from only one discipline, especially if there is no cross-disciplinary dialogue, for example, as in studying the brain mechanisms of creativity without considering the context, or studying the context for creativity without adequate attention being paid to the human brain. It is therefore of paramount importance to have cross-disciplinary dialogue, cooperation and research on creativity, by drawing upon the experience of researchers who specialize in the psychology of creativity, the sociology of creativity, the management of creativity, the education of creativity and the philosophy of creativity, among others.

\section{REFERENCES}

Cheng, S.K. (1999). East-West difference in views on creativity: is Howard Gardner correct? Yes, and no. Journal of Creative Behavior, 33, 2, 112-125.

Cheng, C. \& Shiu, E. (2008). Re-innovation: the construct, measurement, and validation. Technovation, 28, 10, 658-666.

Cooper, R.G. \& Kleinschmidt, E.J. (1986). An investigation into the new product process: steps, deficiencies, and impact. Journal of Product Innovation Management, 3, 2, 71-85.

Crawford, C.M. \& di Benedetto, A. (2011). New Products Management. 10th edition, Boston: McGraw-Hill.

Dawson, P. \& Andriopoulous, C. (2014). Managing Change, Creativity and Innovation. Sage.

Garcia, R. \& Calantone, R. (2002). A critical look at technological innovation typology and innovativeness terminology. A literature review. Journal of Product Innovation Management, 19, 110-132.

Glăveanu, V.P. (2014). The psychology of creativity: a critical reading, Creativity: Theories - Research - Applications, 1, 1, 10-32, DOI: 10.15290/ctra.2014.01.01.02. Morris, M.W. \& Leung, K. (2010). Creativity east and west: perspectives and parallels. Management and Organization Review, 6, 3, 313-327.

Niu, W., \& Sternberg, R. (2002). Comtemporary studies on the concept of creativity: the East and the West. Journal of Creative Behavior, 36, 4, 269-288.

OECD (1991). The nature of innovation and the evolution of the productive system, technology and productivity - the challenge for economic policy. Paris: OECD, pp.303-314.

Placone, R. (1989). Debunking the creativity myths. Bank Systems and Technology, 26, $11,60-62$.

Schmidt, J.B. \& Calantone, R.J. (1998). Are really new product development projects harder to shut down? Journal of Product Innovation Management, 15, 2, 111-123. 
Shiu, E., Hair, J., Bush, R. \& Ortinau, D. (2009a). Marketing Research. New York: McGraw-Hill Higher Education.

Shiu, E. (2009b). Importance of cross-cultural creativity research. In: B. Von Stamm, \& A. Trifilova, (Eds.), The Future of Innovation. Surrey - Burlington: Gower.

Wonder, J. \& Blake, J. (1992). Creativity East and West: intuition vs. Logic. Journal of Creative Behavior, 26, 3, 172-185.

Corresponding author at: Eric Shiu Birmingham Business School, University House, University of Birmingham, Edgbaston Birmingham, B15 2TT, United Kingdom.

E-mail: E.C.Shiu@bham.ac.uk 